\title{
Nursing Actions in practicing inpatient advocacy in a Burn Unit*
}

\author{
Ações dos enfermeiros no exercício da advocacia do paciente \\ internado em um centro de queimados \\ Acciones de los enfermeros en el ejercicio de la defensa del \\ paciente internado en un centro de quemados
}

\begin{abstract}
Aline Carniato Dalle Nogarioํㅜ, Edison Luiz Devos Barlem ${ }^{1}$, Jamila Geri Tomaschewski-Barlem ${ }^{1}$, Valéria Lerch Lunardi ${ }^{1}$, Aline Marcelino Ramos ${ }^{2}$, Aline Cristina Calçada de Oliveira ${ }^{1}$
\end{abstract}

* Extracted from the Project "Advocacia do paciente e coping na enfermagem: possibilidades de exercício de poder mediante vivências de sofrimento moral", Universidade Federal do Rio Grande, 2012.

${ }^{1}$ Universidade Federal do Rio Grande, Escola de Enfermagem, Rio Grande, RS, Brazil.

${ }^{2}$ Universidade Federal do Rio Grande, Escola de Enfermagem, Programa de Pós-Graduação em Enfermagem, Rio Grande, RS, Brazil.

\section{ABSTRACT}

Objective: Understanding nursing actions in the practice of inpatient advocacy in a burn unit. Method: A single and descriptive case study, carried out with nurses working in a referral burn center in southern Brazil. Data were collected through focus group technique, between February and March 2014, in three meetings. Data was analysed through discursive textual analysis. Results: Three emerging categories were identified, namely: (1) instructing the patient; (2) protecting the patient; and (3) ensuring the quality of care. Conclusions: This study identified that the nurses investigated exercised patient advocacy and that the recognition of their actions is an advance for the profession, contributing to the autonomy of nurses and the effectiveness of patients' rights and social justice.

\section{DESCRIPTORS}

Patient Advocacy; Patient Rights; Nurse-Patient Relations; Burns; Nurse's Role. 


\section{INTRODUCTION}

Burns are injuries caused by exposure of the body to direct or indirect action of a heat source, causing partial or total destruction of the skin and its extensions. The leading causes of these injuries are: flames, superheated liquids, extreme temperatures, electricity, friction and chemical or radioactive substances $^{(1-3)}$. It is estimated that the majority of accidents resulting in burns occur in the home environment, mostly affecting children under the age of 5 who are injured by superheated liquids ${ }^{(3)}$.

In Brazil, epidemiological data indicate that each year there are about one million accidents involving burns, resulting in 100,000 hospitalizations and 2,500 deaths from injuries ${ }^{(4)}$. Currently, burn victim patient survival rate has been increasing due to the discovery of new technologies useful in treatments, the implementation of new specialized centers and also the expansion of preventive campaigns. Together, these factors enable a growing improvement in the recovery and quality of life of patients suffering from burns ${ }^{(3)}$.

Burn Assistance Units require a specialized and committed team, composed of professionals from various specialities able to offer comprehensive care, as burn patients are faced with numerous sequelae and physical and psychological limitations that alter their quality of life, either in simple daily activities and even in social relationships ${ }^{(5-6)}$.

Considering that the nurses spend constant time with the patients in the burn centers, they are able to evaluate patients in all dimensions, understanding their physical, psychological and social needs, helping to answer their questions and guiding them to exercise their autonomy in making decisions about their care. Such actions boost and encourage nurses to act as burn patient advocates, often contrary to the interests of health institutions, by confronting a number of morally inadequate policies that disrespect patients' autonomy and their rights ${ }^{(7)}$.

Conceptually, the term advocacy originated from advocate which refers to one who defends the interest of others. Despite evidence indicating the need to pursue it as a career goal in nursing, there still is not a defined concept for patient advocacy. In 1973, international nursing practice codes included patient advocacy as an ethical and legal role for nurses and since then several studies have pointed to actions and features that are intended to assist and expand the exercise of patient advocacy in nursing practice $e^{(7-12)}$.

Thus, several investigations have shown that the actions of nurses as patient advocates are intended to help them in obtaining appropriate health care; defending their rights, ensuring the quality of care; and serving as a link between the patient and the health care environment ${ }^{(7-14)}$. However, it is emphasized that in order to define and describe the actions of nurses in patient advocacy, it is necessary to consider that such actions are not static and fixed, but influenced by particular characteristics of individuals, organizations, relationships, medical conditions and environments ${ }^{(15)}$.

Among some of the attributes for patient advocacy effectiveness are the need to establish effective communication, both with patients and with their family, and other members of the care team ${ }^{(11)}$. The relation of trust established with the patient is able to promote more humanized care, enabling comprehensive defense of their rights by advocacy ${ }^{(16)}$. This practice for the patient's benefit is currently considered an important requirement in nursing care but not an exclusive attribute, although it has not being practiced by professionals from other $\operatorname{areas}^{(9,16)}$.

It important to mention that several health care disciplines involved in the care of burn patients have promoted a significant increase in scientific and clinical research in the area of burns, which resulted in approximately 1,000 articles published in scientific journals in the area of burns in 2013 .These articles address the context of burn victims, covering the areas of critical care, epidemiology, infection, inhalation injury, nutrition and metabolism, pain and itching, psychology, reconstruction and rehabilitation of injuries ${ }^{(6)}$.

However, there are few studies that address the care of burn patients in Brazilian literature ${ }^{(3)}$ and the exercise of $\mathrm{pa}^{-}$ tient advocacy in nursing ${ }^{(17)}$, with the absence of research on burn patient advocacy justifying this study. Thus, the study's objective was to identify the actions of nurses in practicing inpatient advocacy in a burn center.

Identifying the actions performed by nurses seeking to advocate for patients in a burn unit should enable the understanding of the characteristics that define nursing advocacy, favoring the action of these professionals in ethically, humane and effective patient advocacy, thereby demonstrating the relevance of this study.

\section{METHOD}

We conducted research of a case study consisting of a method that investigates a contemporary theme within a specific context, defining and clarifying limits and relationships. A single descriptive case study was conducted ${ }^{(18)}$, seeking to provide extensive description about the patient advocacy phenomenon within the context of a burn center.

The location selected was a Burn Care Reference Center (BCRC) of a hospital in southern Brazil. The BCRC began operations in August 2010 with service capacity for ten patients simultaneously, with a nursing team consisting of a total of seven nurses, one administrative assistant, six assistants, and ten nursing technicians. The unit also had a nurse responsible for continuing education. Other professionals also part of the unit were: one general practitioner, one plastic surgeon, one nutritionist and one physiotherapist per shift. If necessary, psychological support, social assistance or other professional medical specialities were requested and brought in from the general hospital that holds the BCRC. Hygiene and kitchen professionals so routinely perform activities in the unit.

Inclusion criteria for participation in the study were: being a nurse at the BCRC; having at least three years of experience in the unit, since this is considered the minimal training and adaptation time into the unit as perceived by the nurses of this study themselves; having the availability and interest in participating in the previously scheduled meetings for the development of the study.

Study participants were five nurses working in morning, afternoon and evening shifts, as follows: one nurse who played the role in the administrative unit and assisted in the care with three nurses who developed direct patient care; one nurse who commanded the continuous education service in the unit. The age of participants ranged from 25 to 32 years, with the minimum and maximum experience in the unit between 3 and 4 years. 
Three BCRC nurses did not participate in the focus groups, because two were on vacation or away when the groups were developed; one nurse always remained on duty in the unit, even in times of conducting the focus groups to avoid discontinuity of nursing care.

For data collection in the period February-March 2014 we used a focus group technique, which is a type of in-depth interview conducted in groups, allowing for interaction of participants with each other in a process of discussion which is observed and recorded by the moderator. This choice of data collection technique was based on the possibility of obtaining a syncretic, analytical and synthetic vision of data, providing acknowledgement, selective and interpretive readings, respectively ${ }^{(18)}$.

Three one-hour focus group sessions were held, aimed at addressing different aspects of patient advocacy. The organizer of the research team was divided into coordinator and moderator of the focus groups. The coordinator remained responsible for establishing the themes of each meeting and direct dialogue, so that the pre-established objectives were achieved, while the moderator helped to register the group dynamics through recording, while also collaborating in directing the discussions ${ }^{(18)}$.

At the first meeting the initial stimulation was presented: How have you advocated the interests of hospitalized patients in the Burn Center? Therefore, each nursing participant was asked to write a problem-situation experienced in the work unit where it was necessary to advocate for the patient; after which, each nursing participant read the problem situation, instigating the collaboration of other nursing participants for ways to solve the reported problems.

In the second meeting, a diagram containing the summary of the actions which were presented and discussed at the first meeting was presented to the nurses, and each one was asked to name three barriers and three facilitators in carrying out advocacy actions, which were then submitted to group discussion. In the third and last meeting, another diagram containing the advocacy actions was presented to the nurses, as well as a second diagram with the synthesis of barriers and facilitators discussed in the second meeting. After their participation, nurses were asked to develop an overview of patient advocacy actions hospitalized in a Burn Center.
Data analysis was carried out by discursive textual analysis, which can be understood as a process of deconstruction and reconstruction of reading materials. It consists of an integrated process of analysis and synthesis, based on rigorous and indepth reading, describing and interpreting phenomena and speeches. This is then followed by three stages: content uniting; categorization; capture of emerging new ideas ${ }^{(19)}$.

The uniting of content consisted of the researcher's immersion in the transcripts of interviews conducted upon the deconstruction of the text and its fragmentation into units of meaning, according to pragmatic criteria that these units are given according to the framework of burn patient advocacy and the objectives of the research. Upon completion of the uniting, similar meanings were then articulated, which constituted the categorization process. During categorization, relationships were identified between the units of meaning, comparing and grouping units of meaning into three final categories: guiding the patient, protecting the patient and ensuring quality of care. The last step of the analysis, the capture of emerging new ideas, included the description and interpretation of the meanings and senses as constructed from the text ${ }^{(19)}$.

This project was part of a macro project Patient Advocacy and Coping in Nursing: possibilities of the exercise of power upon experiences of moral suffering, Universal Call (474761/2012-6), approved by the local Ethics Committee number 097/2013. The reported statements were coded in three digits, each respectively corresponding to: the meeting number (1-3), letter "E" followed by nurses' identification number and statement number of the meeting.

\section{RESULTS}

Data analysis from the three meetings allowed for the creation of three categories centered on ways to advocate for burn patients: (1) instructing the patient, (2) protecting the patient, and (3) ensuring the quality of care. Patients admitted to the studied $\mathrm{BCRC}$ were in varying stages of hospitalization and progression of the disease, so that the advocacy of actions performed by nurses was carried out according to the specific needs of each patient. Figure 1 shows the model of actions and ways to advocate for patients developed by nurses in a BCRC.

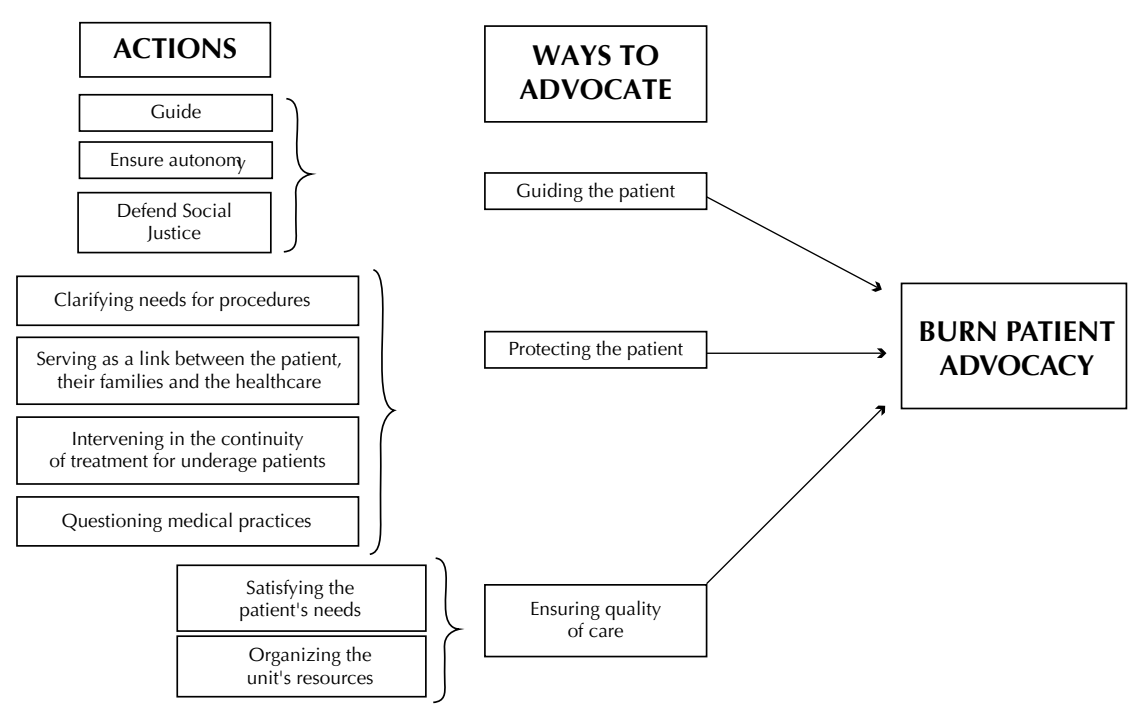

Figure 1 - Model of actions and ways to advocate for the patient developed by nurses in a Burn Care Reference Center in Rio Grande, RS, 2014. 


\section{GUIDING THE PATIENT}

Guidance was described by the group as one of the main actions in the practice of burn patient advocacy since it allowed for ensuring patient autonomy in decision-making, providing benefits during hospitalization and discharge. The guidelines were more directed at information about patients' rights, especially with regards to obtaining medication and the necessary procedures to guarantee them.

We act as patient advocates when counseling about their right to get some medications, especially when discharged from the hospital and they need to make use of ointments and other medicines. When the patient is discharged, sometimes they need to make use of collagenase and other things, we advise them that they can get it from the department; it is their right to receive this medication (1.E1).

I believe that the advocacy of the patient consists in ensuring or facilitating patient access to information related to their problem and assist them in finding ways to ensure their rights as a health system user. I always stress that when they leave here, what they should do, what they should not do and how they should look up service (at Basic Health Unit), such as how they should do their bandages (3.E2).

Similarly, the nursing group realized that guidance was also a way to fight for and defend social justice, because when the individual is unaware of the forms of aid available from the Unified Health System (SUS) and the State, they become even more susceptible to difficulties, demonstrating helpless and vulnerability. By instructing the patient to ensure that they have access and receive the necessary resources for the continuity of their treatment and so they can be imposed in the face of social injustice, nurses demonstrate their concern to advocate for patients beyond the confines of the hospital, ensuring that most patients return home with free access to ointments and expensive medicines.

\section{I think $80 \%$ of them (patients) who leave here can- not buy (medicine). And at least by having the knowledge to inform them (of their rights) this is already an act in defending the patient (1.E3).}

It is the issue of income/money and also the cultural issue itself. Can I (the patient) really go? And will Iget (medication)? And then, when the nurses encourage us, saying: look, you can do it, you have the right to go, when there is someone else saying that it is their right (the patient) by nature (1.E5).

Advocacy is the pursuit of effectiveness of patient rights, seeking to overcome social barriers to solving some obstacles until it reaches the improvement of the patient (3.E1).

\section{Protecting The PATIENT}

With regard to advocacy actions linked to the protec- tion of patients, it became clear that patient advocacy was especially exerted by clarifying procedures and possibilities of sequelae, intervention in the continuity of treatment of underage patients, the questioning of medical procedures and the link between the patient, their families and the health care environment.

As for the clarification of the procedures and consequences the group showed that while analgesia was administered prior to procedures, the pain was a consequence inherent in the manipulation of the injuries which arise from a burn, so that the experience of this situation generated fear and anguish in the patient with the approach of the nurse performing their scheduled care. In this context, the group of nurses reported that they sought to clarify and encourage the patient, explaining their understanding of their condition of pain and fear, but also the need to perform care correctly, and that the after-effects, which at that time were unpredictable, would be minimal.

Patients always say: Ouch, why this bandage?
This pain is horrible. So one of the things I al-
ways say is: This wound will heal, with care it
will heal, but after it does there will be dam-
age that we can't determine now how it will be.
And we try to emphasize this, that the worse is
not now, because later they might come across
an aesthetic or physical damage that will com-
promise your functionality and will compromise
aesthetics. Then they (patients) realize (the need
of dressings) (2.E3).

Another situation highlighted by the group was that underage patients, as well as the elderly had the right to remain accompanied by a family member throughout their hospital stay. Often, the family requested the early hospital discharge for those who suffered trauma, justifying personal problems that made it impossible for them to stay at the hospital. Thus, because they are more vulnerable and they are subject to the decisions of parents or guardians, children needed the intervention of nurses to continue with treatment and avoid future sequelae.

In view of this conflict and the refusal of the family to remain in the unit, nurses needed to activate the institution's social assistance and child protection agency. This action became necessary to avoid the interruption of treatment, as well as the future appearance of injury in the social and working life of the burn victim.

\section{$A$ mother wants to leave and refuses to let her daughter undergo surgery, since skin grafting is recommended for better epithelialization of the wound and reduction of scarring and keloid dam- age, a record in the patient's chart is made. The Child Protection Agency and a social worker have been called in to talk with her. I explained and gave the example of another girl who left and today has an extensive scar on the breast region, like a retrac- tion. We talk, we explain (1.E3).}

The questioning of medical conduct was also highlighted as a way to advocate for the patient, ensuring their protection. Therefore, the group of nurses reported 
that checking medical prescriptions and, when necessary, contacting doctors in charge to try to adapt prescribed medications. This relationship was characterized as professional since it allowed dialogue with the medical team in order to carry out interdisciplinary care, focusing on benefits to patients.

\section{Sometimes we look and see that the prescription is not appropriate, then we call pediatrics and ask how they usually do it there. We get in touch with the doctor who prescribed it and suggest perhaps we could change it (3.E4).}

The group of nurses also pointed out that the burn was a trauma that occurred abruptly, surprising the person who suffered the accident and their family, so that the sudden hospitalization caused even more suffering, distress and fear for the people involved, especially regarding the lack of knowledge of the care and hospitalization in the unit, the rules of the institution and the policies. Thus, the group of nurses demonstrated that they exerted advocacy when they received and clarified patients and families about the specificity of the burn center, establishing a link between them and the health care environment, so that the hospital stay had the least possible traumatic impact.

\section{(...) a mother came terrified with a boy. When she arrived we started to talk and explain that it was routine and she got calmer (2.E1).}

I believe that exercising patient advocacy is working towards them, exercising communication and dialogue between staff, patients and families, enabling care (3.E3).

\section{ENSURING THE QUALITY OF CARE}

In this category, the nursing actions in exercising burn patient advocacy were associated to ensure the quality of care by satisfying the needs of patients and the organization of the unit's resources.

Regarding meeting the needs of patients, the group of nurses mentioned that hospitalized patients when minors or elderlies had the right to a companion; however, due to the clinical specificity of burn patients, nurses assessed the situations individually, requesting monitoring of patients, even if by law they did not have that right. Adults, in many cases, required companions because of their type of burn (when it affected their hands it made them more dependent), or the depressive condition that often assails burn patients.

Those who can have companions are minors and the elderly, but sometimes when we see that an adult patient is in need, we talk with a family member and ask someone to stay with them (3.E2).

Often, the administration does not let them in. Before it was up to us, we called to authorize their entry and that was alright, but not now. We must always explain and request it (3.E3).

With regard to ensuring the quality of care through the organization of resources, there were actions found to be intended changes and improvements in the BCRC unit, such as the management of available resources to achieve bathing and dressing, from gauze and ointments up to the bandages of high technology, benefiting hospitalized patients in general. Thus, the group of nurses highlighted the organization and the availability of technological resources in the unit as an effective means of ensuring quality care and effectiveness.

\section{For everything we seek a solution. Regarding the unit, it seeks to provide the necessary material, to always be organized for the staff to be able to work doing their best. Providing the material and organizing it all is also a way to facilitate work to be developed effectively (2.E3).}

Finally, the nursing group pointed out that discussing and reflecting on their actions in practicing burn patient advocacy allowed them to realize how their behavior could positively influence the lives of patients under their care. Similarly, the group pointed out that they were responsible for the patient from admission until after discharge, worrying about the continuity of care and the availability of resources outside of the BCRC, especially in the hometowns of those who sought the service, for they knew that burn patients are still an unknown type of patient in many places.
While they are here (in the BCRC) the profes- sionals are accustomed to this type of injury they have, but in other units, not always. Depending on the city, often there are no resources, so I al- ways consider that side of the advocacy (3.E2).

\section{DISCUSSION}

It is noteworthy that the patient's advocate role is assigned to nurses because of their relationship and time spent with their patients, but there is still no defined concept which can lead these professionals to face difficulties when faced with the lack of knowledge of their real assignment ${ }^{(20)}$. From the results of this study, it became clear that several nursing actions that nurses develop in order to practice burn patient advocacy are based on guiding, protecting and ensuring the quality of care provided to patients.

As a result, recognizing the actions of nurses in practicing burn patient advocacy may be a breakthrough for the profession, considering that nurses may feel helpless in situations that require positioning themselves in defense of patient rights, which could affect the integrity and the quality of care ${ }^{(20)}$.

Participants of this study reported guidance as a way to advocate for patients because they understood that through it they could clarify the patient as to the numerous questions that arose during hospitalization, ensuring that they were sufficiently informed to exercise their autonomy in making decisions about their care. Similarly, studies in different contexts and clinical situations have shown that patient advocacy can be considered a moral commitment of nurses, aimed especially at counseling patients about their rights and helping them in the decision-making process and ensuring the exercise of their autonomy ${ }^{(7-10,14,17)}$.

Nurse participants in this study reported that by guiding their patients about care in the period after hospital discharge, they were practicing advocacy because outside of the 
burn center environment, the patient could be faced with a lack of professionals and a lack of resources to meet their specific requirements. Thus corroborating the literature on the subject, the patients with unfavorable socioeconomic situations could not acquire the proper materials on their own to continue treatment, especially ointments which have high costs and require nursing guidelines about the difficulties they may face outside the hospital, as pointed out in studies with burn patients ${ }^{(1,6,21)}$.

The search for social rights and especially the struggle for social justice was also described by nurse participants of the research as an important form of advocacy, which is consistent with a study that analyzed the concept of patient advocacy and identified that upholding social justice and protecting the autonomy of patients are fundamental characteristics of defending the interests of patients ${ }^{(22)}$. The model of social advocacy, described in 1989, reaffirms the need for the practice of advocacy by nurses for individual patients, but goes beyond health institutions, causing the participation of nurses in social change, seeking equitable access to health care for patients and clinics and correcting social injustices that violate their rights and values ${ }^{(23)}$.

Therefore, the search for the patient's rights strengthens the role of the nurse as an advocate and reaffirms the defense that these actions are essential components of this profession ${ }^{(9)}$, demonstrating that nurses are concerned about their patients beyond the hospital stay, promoting autonomy the patient so that they may seek a level playing field, fairness and quality of care also outside the hospital (14).

Another aspect highlighted in this study concerns the procedures and the resulting consequences of burns; issues which, according to participant nurses, need a broader approach of the team responsible for the care, as the momentary fear of pain generates negative reactions to treatment. At that time, nurses must seek to directly interfere in the guidelines and motivating the patients will enable in the delivery of care, as these are necessary to the success of treatment ${ }^{(24)}$.

Still, it is the responsibility of the professionals to establish measures to reduce or eliminate pain during the procedures, primarily through adequate analgesia ${ }^{(24,25)}$. $\mathrm{Pa}-$ tients in pain often require that nurses provide advocacy to improve pain management, as they may be unaware of the therapeutic measures available and their rights. In this way and in guiding patients to order medications, having their pain treated and defending their unmet needs are important responsibilities of nurses in exercising patient advocacy $^{(10)}$.

Still, it became clear that fears that arise during the hospital stay affect both the patient and the family. In this sense, the situations related to underage patients should be observed with special attention, since these relationships are often fraught with conflict between the nurse and the person responsible for a minor. The nurse, when faced with the need for a procedure that can eventually improve the quality of life and self-esteem of the patient often seeks to act as a patient advocate by questioning the family decision to not carry out certain procedures for fear or insecurity ${ }^{(14,26)}$, even fighting against the wishes of early hospital discharge requested by family.

The cases where care is refused by those family members responsible for an underage patient require that the conflict is brought to other professionals, so that the multi-professional assistance is based on guidelines of social welfare, psychology, child protection agency and others, and therefore can contribute in solving the situation ${ }^{(21)}$. The nurses in this study reported that they sought to guide the family in relation to all necessary care, trying to establish an effective communication level but not limiting them to purely technical care, so that the psychological needs of the family could be met by staff, resulting in minimizing negative responses to a burn situation.

Another important action highlighted in the speeches of respondents was the need for questioning the prescription, especially in situations where drug doses seemed to be inadequate for patients. Nurses emphasized this as a positive form of advocacy, because their actions allowed the establishment of an effective communication scenario, strengthening the relationship between doctors and nurses, thus bringing benefits to patient care ${ }^{(24)}$.

In this sense, the nature of the nurse's relationship with the other members of the healthcare team can be considered a strong influence on the role of nurses as advocates, especially when the values and goals of care are shared, enhancing the patient-centered care and highlights the importance of multidisciplinary teams and effective communication ${ }^{(27)}$.

With regard to actions related to ensuring the quality of care, it is worth noting that underage patients and the elderly have the right to remain accompanied throughout hospitalization. However, adult patients who do not have that right must be evaluated daily, for the isolation from their relatives is associated with fear, dependence and negativity in their current situation, and can make a depressive disorder very difficult to reverse ${ }^{(24)}$. In this context, nurses believe in acting in defense of their patients when they seek to evaluate their cases individually, in order to meet the needs of individuals and making exceptions when necessary, allowing the constant presence of a family member in the unit ${ }^{(22)}$.

With regard to ensuring the quality of care, mediated by unit resource organization similar to the results of this study, we found that organizational advocacy involves actions that seek changes and improvements in the institutional level, benefiting patients in general ${ }^{(28)}$. Therefore, when the nurse demands better working conditions, they are indirectly advocating for patients in an attempt to modify and qualify the environments in which they operate through their efforts of ensuring the quality of care provided ${ }^{(17)}$.

The limitation of this study was related to the nature and fulfillment in a unique context (being a burn center located in southern Brazil), which does not allow for generalizing the results. Likewise, the nature of case studies does not allow replication to other situations. 


\section{CONCLUSION}

The results found showed that the main actions of nurses in exercising patient advocacy in the context of the researched burn center can be translated into attitudes of guiding the patient, protecting them and ensuring quality of care. Such actions can positively influence the life of a burn victim and their hospital stay, or even more so in their postdischarge period, a factor of concern for the respondents.

In doing so, the actions for the establishment of conditions of autonomy and social justice can be highlighted as the main results of this study, given that they evidence the concern and commitment of nurses to improve the health level in individual and collective areas, pushing the boundaries of hospitals.

Finally, it seems relevant to question: Would the results of this study be similar in other burn centers? In this context, it is necessary to carry out further studies in support of the dissemination of knowledge and building strategies to strengthen nursing actions as patient advocates, thus contributing to the autonomy of the nurse and the enforcement of patient rights and social justice.

\section{RESUMO}

Objetivo: Conhecer as ações dos enfermeiros no exercício da advocacia do paciente internado em um centro de queimados. Método: Estudo de caso único e descritivo, realizado com enfermeiros atuantes em um centro de referência de queimados, na região sul do Brasil. A coleta de dados ocorreu por meio da técnica de grupo focal, entre fevereiro e março de 2014, sendo realizados três encontros. Os dados foram estudados conforme análise textual discursiva. Resultados: Foram identificadas três categorias emergentes, quais sejam: (1) orientar o paciente; (2) proteger o paciente; e (3) garantir a qualidade do cuidado. Conclusão: Este estudo possibilitou identificar que os enfermeiros pesquisados exerciam a advocacia de seus pacientes e que o reconhecimento de suas ações constitui um avanço para a profissão, contribuindo para a autonomia do enfermeiro e a efetivação dos direitos dos pacientes e da justiça social.

\section{DESCRITORES}

Defesa do Paciente; Direitos do Paciente; Relações Enfermeiro-Paciente; Queimaduras; Papel do Profissional de Enfermagem.

\section{RESUMEN}

Objetivo: Conocer las acciones de los enfermeros en el ejercicio de la defensa del paciente internado en un centro de quemados. Método: Estudio de caso único y descriptivo, llevado a cabo con enfermeros actuantes en un centro de referencia de quemados, en la región sur de Brasil. La recogida de datos ocurrió mediante la técnica de grupo focal, entre febrero y marzo de 2014, siendo realizados tres encuentros. Los datos fueron estudiados conforme al análisis textual discursivo. Resultados: Se identificaron tres categorías emergentes, a saber: (1) orientar al paciente; (2) proteger al paciente; y (3) asegurar la calidad del cuidado. Conclusión: Este estudio posibilitó identificar que los enfermeros investigados ejercitaban la defensa de sus pacientes y que el reconocimiento de sus acciones constituye un avance para la profesión, al contribuir con la autonomía del enfermero y la puesta en marcha de los derechos de los pacientes y la justicia social.

\section{DESCRIPTORES}

Defensa del Paciente; Derechos del Paciente; Relaciones Enfermero-Paciente; Quemaduras; Rol de la Enfermera.

\section{REFERENCES}

1. den Hollander D, Albert M, Strand A, Hardcastle TC. Epidemiology and referral patterns of burns admitted to the Burns Centre at Inkosi Albert Luthuli Central Hospital, Durban. Burns. 2014;40(6):1201-8.

2. Montes SF, Barbosa MH, Sousa Neto AL. Clinical and epidemiological aspects of burned patients hospitalized in a teaching hospital. Rev Esc Enferm USP [Internet]. 2011 [cited 2014 July 22];45(2):369-73. Available from: http://www.scielo.br/pdf/reeusp/v45n2/en_v45n2a09.pdf

3. Stergiou-Kita M, Grigorovich A, Gomez M. Development of an inter-professional clinical practice guideline for vocational evaluation following severe burn. Burns. 2014;40(6):1149-63.

4. Ricci H, Gonçalves N, Gallani MC, Ciol MA, Dantas RA, Rossi LA. Assessment of the health status in Brazilian burn victims five to seven months after hospital discharge. Burns. 2014;40(4):616-23.

5. Stavrou D, Weissman O, Tessone A, Zilinsky I, Holloway S, Boyd J, et al. Health related quality of life in burn patients: a review of the literature. Burns. 2014;40(5):788-96.

6. Sen S, Palmieri T, Greenhalgh D. Review of burn research for the year 2013. J Burn Care Res. 2014;35(5):362-8.

7. Hanks RG. Development and testing of an instrument to measure protective nursing advocacy. Nurs Ethics. 2010;17(2):255-67.

8. Vaartio H, Leino-Kilpi H, Suominen T, Puukka P. Nursing advocacy in procedural pain care. Nurs Ethics. 2009;16(3):340-62.

9. Hanks RG. The medical-surgical nurse perspective of advocate role. Nurs Forum. 2010;45(2):97-107.

10. Ware LJ, Bruckenthal P, Davis GC, O'Conner-Von SK. Factors that influence patient advocacy by pain management nurses: results of the American society for pain management nursing survey. Pain Manag Nurs. 2011;12(1):25-32.

11. Josse-Eklund A, Jossebo M, Sandin-Bojö AK, Wilde-Larsson B, Petzäll K. Swedish nurses' perceptions of influencers on patient advocacy: a phenomenographic study. Nurs Ethics. 2014;21(6):673-83.

12. Cole C, Wellard S, Mummery J. Problematising autonomy and advocacy in nursing. Nurs Ethics. 2014;21(5):576-82.

13. Negarandeh R, Oskouie F, Ahmadi F, Nikravesh M, Hallberg IR. Patient advocacy: barriers and facilitators. BMC Nurs. 2006;5:3. 
14. Pavlish C, Ho A, Rounkle A. Health and human rights advocacy: perspectives from a Rwandan refugee camp. Nurs Ethics. 2012;19(4):538-49.

15. Simmonds AH. Autonomy and advocacy in perinatal nursing practice. Nurs Ethics. 2008;15(3):360-70.

16. Barlem ELD, Lunardi VL, Tomaschewski JG, Lunardi GL, Lunardi Filho WD, Schwonke CRGB. Moral distress: challenges for an autonomous nursing professional practice. Rev Esc Enferm USP [Internet]. 2013 [cited 2014 July 22];47(2):506-10. Available from: http://www.scielo. $\mathrm{br} / \mathrm{pdf} /$ reeusp/v47n2/33.pdf

17. Tomaschewski-Barlem JG. O exercício da advocacia do paciente pelos enfermeiros: uma perspectiva foucaultiana [tese doutorado]. Rio Grande: Programa de Pós- Graduação em Enfermagem, Universidade Federal do Rio Grande; 2014.

18. Gil AC. Estudo de caso. São Paulo: Atlas; 2009.

19. Moraes R, Galiazzi MC. Análise textual discursiva. 2a ed. Ijuí: Unijuí; 2013.

20. Mahlin M. Individual patient advocacy, collective responsibility and activism within professional nursing associations. Nurs Ethics. 2010;17(2):247-54.

21. Silva RMA, Castilhos APL. A identificação de diagnósticos de enfermagem em paciente considerado grande queimado: um facilitador para implementação das ações de enfermagem. Rev Bras Queimaduras. 2010;9(2):60-5.

22. Bu X, Jezewski MA. Developing a mid-range theory of patient advocacy through concept analysis. J Adv Nurs. 2007;57(1):101-10.

23. Fowler MD. Social advocacy: ethical issues in critical care. Heart Lung. 1989;18(1):97-9.

24. Shepherd L, Begum R. Helping burn patients to look at their injuries: How confident are burn care staff and how often do they help? Burns. 2014;40(8):1602-8.

25. Park E, Oh H, Kim T. The effects of relaxation breathing on procedural pain and anxiety during burn care. Burns. 2013;39(6):1101-6.

26. Smith AL, Murray DA, McBride CJ, McBride-Henry K. A comparison of nurses' and parents' or caregivers' perceptions during pediatric burn dressing changes: an exploratory study. J Burn Care Res. 2011;32(2):185-99.

27. Thacker KS. Nurses' advocacy behaviors in end-of-life nursing care. Nurs Ethics. 2008;15(2):174-85.

28. O'Connor T, Kelly B. Bridging the gap: a study of general nurses' perceptions of patient advocacy in Ireland. Nurs Ethics. 2005;12(5):453-67.

Financial Support: Conselho Nacional de Desenvolvimento Científico e Tecnológico (CNPq). Process 474761/2012-6. 